\title{
Impact of Dental Diseases on Quality- Adjusted Life Expectancy in US Adults
}

\author{
Y. Matsuyama ${ }^{1,2,3}{ }^{\mathbb{D}}$, G. Tsakos ${ }^{3}$, S. Listl ${ }^{4,5}$, J. Aida ${ }^{6}$, \\ and R.G. Watt ${ }^{3}$
}

\begin{abstract}
Comparing the burden of dental conditions to other health outcomes provides useful insight for public policy. We aimed to estimate quality-adjusted life expectancy (QALE) loss due to dental conditions in the US adult population. Social inequalities in QALE loss by dental conditions were also examined. Data from 3 cross-sectional waves of the National Health and Nutrition Examination Survey (NHANES waves 200I to 2002, 2003 to 2004, and 20I I to 20I2) were pooled and analyzed. The average age of study participants ( $n=$ $9,445)$ was $48.4 \mathrm{y}$. Disutility scores were derived from self-rated health and the numbers of physically unhealthy days, mentally unhealthy days, and days with activity limitation, employing a previously published algorithm. The associations between the disutility scores and the numbers of decayed teeth, missing teeth, and periodontitis were examined by multiple linear regression stratified by age groups (20-39, $40-59$, and $\geq 60$ y), adjusted for other covariates (age, sex, wave fixed effect, educational attainment, smoking, and diabetes). The QALE loss due to dental conditions at the age of 20 was estimated using life tables. Decayed and missing teeth, but not periodontitis, were associated with a larger disutility score. The coefficient for decayed teeth was larger among the older population, whereas that of missing teeth was smaller among them. The estimated QALE loss was 0.43 y (95\% confidence interval $[\mathrm{Cl}], 0.28-0.59)$, which reached $5.3 \%$ of QALE loss (8.15 y; 95\% Cl, 8.03-8.27) due to overall morbidity. There were clear social gradients in QALE loss by dental conditions across the life course, and people with high school or less education had 0.32 y larger QALE loss in total compared with people with college or more education. This study suggests that improvements in people's dental health may yield substantial gains in population health and well-being. The necessity of more comprehensive public health strategies is highlighted.
\end{abstract}

Keywords: quality of life, dental public health, epidemiology, caries, periodontal disease(s)/periodontitis, edentulous/edentulism

\section{Background}

Dental diseases are highly prevalent worldwide (Kassebaum et al. 2017) and substantially affect quality of life (Haag et al. 2017). They are chronic and cumulative in nature (Heilmann et al. 2015) and rapidly increasing across the life course (Kassebaum et al. 2017). The trajectory of dental status is socially patterned, whereby people from a lower socioeconomic position are more likely to have worse dental status at various stages of life (Nicolau et al. 2007; Steele et al. 2015; Watt et al. 2015). Providing a comprehensive picture of the dynamics and social distribution of the health burden due to various dental conditions would provide a unique perspective for shaping public health policy.

Comparing various health outcomes on a single scale is important to evaluate the relative impact of different diseases in society and to prioritize the allocation of health care resources. One way to make such comparisons is facilitated by the concept of quality-adjusted life years (QALY), which represents population health by considering the duration and quality of life. A QALY is calculated by multiplying the duration of time spent with a certain health status and the utility score, an indicator of various health states based upon population preference, whereby death is scored as 0 and full health as 1 (Whitehead and Ali 2010; Neumann and Cohen 2018). Thus, 1 QALY indicates spending a year in the hypothetical "perfect" or "the most desirable" health state (Neumann and Cohen 2018). The QALY can also be summarized in a lifetime horizon indicating expected duration and quality of remaining life at the specific age, that is, quality-adjusted life expectancy (QALE) (Rosenberg et al. 1999).

QALE may also vary between different socioeconomic groups; the gradients in QALE have been reported with the difference of $11 \mathrm{y}$ at birth by multiple deprivation in the United

\footnotetext{
'Department of Global Health Promotion, Tokyo Medical and Dental University (TMDU), Bunkyo-ku, Japan

${ }^{2}$ Japan Society for the Promotion of Science, Chiyoda-ku, Japan ${ }^{3}$ Department of Epidemiology and Public Health, University College London, London, UK

${ }^{4}$ Department of Dentistry-Chair for Quality and Safety of Oral Healthcare, Radboud University Medical Center, Nijmegen, Netherlands ${ }^{5}$ Department of Conservative Dentistry-Section for Translational Health Economics, Heidelberg University Hospital, Heidelberg, Germany ${ }^{6}$ Department of International and Community Oral Health, Tohoku University Graduate School of Dentistry, Sendai, Japan
}

A supplemental appendix to this article is available online.

\section{Corresponding Author:}

Yusuke Matsuyama, Department of Global Health Promotion, Tokyo Medical and Dental University (TMDU), I-5-45, Yushima, Bunkyo-ku,

Tokyo, II3-85I0, Japan.

Email: matsuyama-thk@umin.org 
Kingdom (Love-Koh et al. 2015) and 8 y at $25 \mathrm{y}$ of age by educational attainment in the Netherlands (Gheorghe et al. 2016). However, to our knowledge, no studies have reported the dental-related QALE loss and the extent of related social inequalities.

The present study aimed to estimate QALE loss due to decayed teeth, missing teeth, and periodontitis and its social pattern in the US adult population. These 3 dental conditions were selected because they represent the 3 most prevalent dental conditions (Kassebaum et al. 2017). Our estimate in the present study does not include other oral conditions such as oral cancer.

\section{Methods}

\section{Data Source}

Our analyses are based on pooled cross-sectional data from 3 waves of the National Health and Nutrition Examination Survey (NHANES waves 2001 to 2002, 2003 to 2004, and 2011 to 2012). The NHANES survey employs a stratified multistage probability sampling of the civilian noninstitutionalized population of the United States and collects data through interviews and clinical examinations. More detail about the survey has been reported elsewhere (Centers for Disease Control and Prevention 2012). Participants aged $\geq 20$ y who completed the dental examination and without missing information on the variables were included in the analyses (Fig. 1). The present study was based on analyses of secondary anonymous data, and no ethics approval was required.

\section{Variables}

The dependent variable was disutility score, which was derived from answers on self-rated health and numbers of physically unhealthy days, mentally unhealthy days, and days with activity limitation during the past 30 days. These 4 variables were mapped to the EQ-5D index (Brooks 1996), a scale of health utility ranging from 0 (death) to 1 (perfect health), employing a previously published algorithm (Jia et al. 2011). The algorithm has been validated using representative samples of the US adult population, and the bias compared with the actual EQ-5D scale was estimated to be less than 1\% (Jia et al. 2011). The mapped EQ-5D utility scores were subtracted from 1 and used as a continuous variable indicating disutility to estimate dental conditions' burden directly. The detail of this procedure is described in Appendix.

The explanatory variables were numbers of decayed teeth, missing teeth due to dental diseases, and teeth with periodontitis. Third molars were not included since their periodontal
National Health and Nutrition Examination Survey (NHANES) waves 2001-2002, 2003-2004, and 2011-2012

$(\mathrm{N}=30,917 ; 11,039$ from wave 2001-2002, 10,122 from wave 2003-2004, and 9,756 from wave 2011-2012)

Missing information on variables $(\mathrm{n}=1,070 *)$

- $\quad$ Physically unhealthy days $(n=667)$

- Mentally unhealthy days $(n=671)$

- Activity limitation days $(n=666)$

- $\quad$ Education $(n=309)$

- $\quad$ Smoking status $(n=11)$

- Diabetes $(\mathrm{n}=6)$

- $\quad$ Number of missing teeth $(\mathrm{n}=1)$

- $\quad$ Number of periodontal disease $(n=111)$

*Some were duplicated
Respondents in study sample $(\mathrm{n}=9,445)$

Figure I. Flowchart to obtain respondents for analyses.

status was not examined. Periodontitis was defined by $\geq 3 \mathrm{~mm}$ of loss of attachment and $\geq 4 \mathrm{~mm}$ of pocket depth on the same periodontal sites (Centers for Disease Control and Prevention 2004). Full-mouth assessment was conducted for periodontal disease in wave 2011 to 2012, while 3 facial sites in 2 randomly selected quadrants were assessed in the former 2 waves. To consider the difference, information on periodontitis in wave 2011 to 2012 was also randomly selected in the present study.

Age (continuous), sex (men, women), educational attainment (high school or less, less than college, college or more), smoking status (never smoker, former smoker, current smoker), diabetes (yes, no), and survey wave fixed effects were adjusted for.

\section{Statistical Analyses}

We employed a 3-step approach to estimate QALE loss. First, the associations between dental conditions and disutility score were examined by multiple linear regression models: unadjusted (model 1), adjusted for all covariates separately for each dental condition (model 2), and adjusted for all covariates and the 3 variables on dental conditions included together (model 
Table I. Demographic Characteristics of Respondents ( $n=9,445$; Nonweighted).

\begin{tabular}{|c|c|c|c|c|c|c|c|c|c|}
\hline & \multirow{2}{*}{$\begin{array}{l}\text { Number of } \\
\text { Respondents }\end{array}$} & \multicolumn{2}{|c|}{ Disutility Score } & \multicolumn{2}{|c|}{ Decayed Teeth } & \multicolumn{2}{|c|}{ Missing Teeth } & \multicolumn{2}{|c|}{ Periodontitis $^{\mathrm{a}}$} \\
\hline & & Mean & SD & Mean & SD & Mean & SD & Mean & SD \\
\hline \multicolumn{10}{|l|}{ NHANES wave } \\
\hline 2001 & 3,298 & 0.13 & 0.09 & 0.67 & 1.83 & 3.37 & 5.50 & 0.27 & 0.96 \\
\hline 2003 & 2,975 & 0.13 & 0.09 & 0.87 & 1.81 & 3.83 & 5.93 & 0.20 & 0.83 \\
\hline 2011 & 3,172 & 0.15 & 0.11 & 0.67 & 1.81 & 6.96 & 9.08 & 0.79 & 1.81 \\
\hline \multicolumn{10}{|l|}{ Age } \\
\hline 20-39 & 3,352 & 0.12 & 0.08 & 0.94 & 2.17 & 1.02 & 2.77 & 0.18 & 0.87 \\
\hline $40-59$ & 3,286 & 0.14 & 0.11 & 0.76 & $\mathrm{I} .77$ & 3.99 & 5.65 & 0.61 & 1.59 \\
\hline$\geq 60$ & 2,807 & 0.15 & 0.10 & 0.46 & 1.30 & 9.99 & 9.13 & 0.51 & 1.32 \\
\hline \multicolumn{10}{|l|}{ Sex } \\
\hline Men & 4,694 & 0.13 & 0.09 & 0.84 & 1.99 & 4.70 & 7.18 & 0.58 & 1.55 \\
\hline Women & 4,751 & 0.15 & 0.10 & 0.63 & 1.63 & 4.74 & 7.23 & 0.27 & 0.98 \\
\hline \multicolumn{10}{|l|}{ Education } \\
\hline High school or less & 2,409 & 0.16 & 0.11 & 1.16 & 2.31 & 6.90 & 8.40 & 0.63 & 1.58 \\
\hline Less than college & 4,725 & 0.14 & 0.10 & 0.75 & 1.81 & 4.79 & 7.13 & 0.42 & 1.32 \\
\hline College or more & 2,311 & 0.12 & 0.08 & 0.26 & 0.91 & 2.30 & 4.89 & 0.21 & 0.85 \\
\hline \multicolumn{10}{|l|}{ Smoking status } \\
\hline Never smoker & 5,068 & 0.13 & 0.09 & 0.57 & 1.47 & 3.62 & 6.24 & 0.29 & 1.03 \\
\hline Former smoker & 2,369 & 0.14 & 0.10 & 0.54 & 1.50 & 6.38 & 8.25 & 0.44 & 1.26 \\
\hline Current smoker & 2,008 & 0.16 & 0.11 & 1.38 & 2.63 & 5.54 & 7.64 & 0.75 & 1.81 \\
\hline \multicolumn{10}{|l|}{ Diabetes } \\
\hline Not diabetes & 8,478 & 0.13 & 0.09 & 0.74 & 1.85 & 4.15 & 6.72 & 0.39 & 1.26 \\
\hline Diabetes & 967 & 0.18 & 0.13 & 0.66 & $|.5|$ & 9.69 & 9.15 & 0.68 & 1.60 \\
\hline Total & 9,445 & 0.14 & 0.10 & 0.73 & 1.82 & 4.72 & 7.20 & 0.42 & 1.30 \\
\hline
\end{tabular}

NHANES, National Health and Nutrition Examination Survey.

${ }^{a}$ The number of teeth with pocket depth $\geq 4 \mathrm{~mm}$ and loss of attachment $\geq 3 \mathrm{~mm}$ on the same periodontal site.

3 ). The regression models were stratified by age group (20 to 39,40 to 59 , and $\geq 60$ y old), and sampling weight was applied.

Second, to describe the impact of dental conditions in the US population, average disutility due to dental conditions for every $5 \mathrm{y}$ of age was calculated by multiplying the coefficients in model 3 and the average number of decayed teeth, missing teeth, and periodontitis in the respective age group.

Third, sex-, educational attainment-, and disease-specific QALE loss at the age of 20 was estimated by combining the estimation at step 2 and the information on life tables for the US population in 2011 (Xu et al. 2015). The detail of this procedure is described in Appendix. QALE loss due to overall morbidity was also estimated to assess how much of it was due to dental conditions.

We used STATA MP version 15.1 (Stata Corp.) for all analyses and followed STROBE guidelines.

\section{Results}

In total, 9,445 participants (average age $=48.4 \mathrm{y}$ ) were included in the analyses (Fig. 1). Table 1 describes the demographic characteristics of the respondents. Higher disutility scores were observed among the older participants, women, those with lower educational attainment, smokers, and those with diabetes. Appendix Table 1 shows the distribution of the variables used to derive the disutility score.

Table 2 shows the results from the regression analyses. Decayed teeth and missing teeth were significantly associated with a higher disutility score in all age groups, while the association between disutility score and periodontitis was not significant among those aged 20 to $39 \mathrm{y}$ and $\geq 60 \mathrm{y}$ (model 1). The associations between decayed teeth and the disutility score among those aged 20 to $39 \mathrm{y}$ and periodontitis among the 40to 59-y-olds were not significant after adjusting for covariates (model 2). Including all 3 dental conditions together did not affect the estimates (model 3). Overall, the coefficient on decayed teeth was larger among the older population, while that of missing teeth was smaller among them.

Figure 2 illustrates the average of disease-specific disutility at every $5 \mathrm{y}$ of age by educational attainment. The total disutility increased with aging until the age of $60 \mathrm{y}$ mainly due to increased disutility with age from missing teeth. The bars for periodontitis were below 0 , representing negative but not significant coefficients (Table 2, model 3). There was a clear social gradient with participants with lower educational attainment having larger disutility at all stages of life.

Table 3 and Appendix Figure 1 summarize the estimated QALE loss at age $20 \mathrm{y}$. The average QALE loss was $0.43 \mathrm{y}$ (95\% confidence interval [CI], 0.28-0.59), which represents $5.3 \%$ in QALE loss due to overall morbidity $(8.15 \mathrm{y} ; 95 \% \mathrm{CI}$, 8.03-8.27). The QALE loss due to dental conditions and the percentage due to overall morbidity by educational strata was $0.57(6.5 \%), 0.38(5.2 \%)$, and $0.25(3.2 \%)$ for high school or less, less than college, and college or more, respectively. A social gradient in the total QALE loss by educational attainment was observed and the absolute difference between people 
Table 2. Association between Oral Condition and Disutility Score $(n=9,445)$ : Sampling Weight Applied.

\begin{tabular}{|c|c|c|c|c|c|c|}
\hline & \multicolumn{2}{|c|}{ Model I } & \multicolumn{2}{|c|}{ Model 2} & \multicolumn{2}{|c|}{ Model 3} \\
\hline & $\beta$ & $95 \% \mathrm{Cl}$ & $\beta$ & $95 \% \mathrm{Cl}$ & $\beta$ & $95 \% \mathrm{Cl}$ \\
\hline \multicolumn{7}{|l|}{ Age 20 to 39} \\
\hline Decayed teeth & 0.0032 & 0.0012 to $0.005 \mathrm{I}$ & 0.0016 & -0.0003 to 0.0035 & 0.0013 & -0.0007 to 0.0032 \\
\hline Missing teeth & 0.0038 & 0.0022 to 0.0054 & 0.0023 & 0.0008 to 0.0038 & 0.0021 & 0.0006 to 0.0037 \\
\hline Periodontitis ${ }^{\mathrm{a}}$ & 0.0008 & -0.0026 to 0.0042 & -0.0023 & -0.0057 to 0.0011 & -0.0027 & -0.0062 to 0.0008 \\
\hline \multicolumn{7}{|l|}{ Age 40 to 59} \\
\hline Decayed teeth & 0.0079 & 0.0049 to 0.0109 & 0.0048 & 0.0017 to 0.0079 & 0.0044 & 0.0013 to 0.0074 \\
\hline Missing teeth & 0.0033 & 0.0024 to 0.0042 & 0.0015 & 0.0006 to 0.0025 & 0.0014 & 0.0004 to 0.0023 \\
\hline Periodontitis ${ }^{\mathrm{a}}$ & 0.0032 & 0.0004 to 0.0060 & -0.0012 & -0.0039 to 0.0015 & -0.0016 & -0.0043 to 0.0011 \\
\hline \multicolumn{7}{|l|}{ Age $\geq 60$} \\
\hline Decayed teeth & 0.0080 & 0.0026 to 0.0134 & 0.0059 & 0.0005 to 0.0113 & 0.0059 & 0.0005 to 0.0113 \\
\hline Missing teeth & 0.0017 & 0.0012 to 0.0021 & 0.0008 & 0.0003 to 0.0013 & 0.0008 & 0.0003 to 0.0013 \\
\hline Periodontitis ${ }^{\mathrm{a}}$ & 0.0013 & -0.0022 to 0.0048 & 0.0004 & -0.0030 to 0.0038 & 0.0002 & -0.0032 to 0.0036 \\
\hline
\end{tabular}

$\beta$, nonstandardized coefficient; $\mathrm{Cl}$, confidence interval. Model I: crude; each oral condition was separately included. Model 2: adjusted for age, sex, wave fixed effect, education, smoking, and diabetes. Model 3: model $2+$ all oral conditions were included together.

${ }^{\mathrm{a}}$ The number of teeth with pocket depth $\geq 4 \mathrm{~mm}$ and loss of attachment $\geq 3 \mathrm{~mm}$ on the same periodontal site.

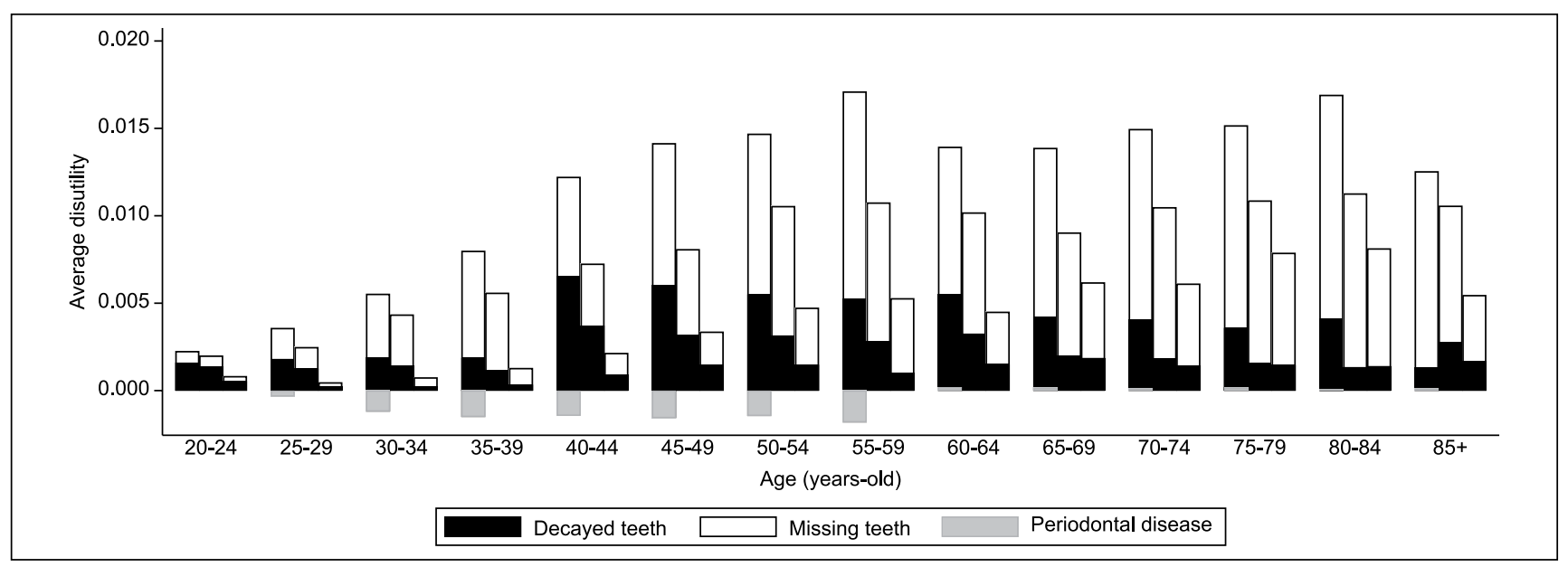

Figure 2. Average disutility due to oral conditions among US population by age groups; the 3 graphs in the same age group show each educational attainment: high school or less (left), less than college (middle), and college or more (right).

educated up to high school level or lower and those with college or more education was $0.32 \mathrm{y}$. The QALE loss due to dental conditions shared a higher proportion of QALE loss due to overall morbidity in the lower educated group (Appendix Fig. 1).

\section{Discussion}

This study is the first to report the contribution of dental conditions to QALE loss. Decayed teeth and missing teeth were significantly associated with disutility, while periodontitis was not. The marginal effect of 1 untreated decayed tooth on the disutility score was higher among the older population, while that of 1 missing tooth was lower among them. The QALE loss at age $20 \mathrm{y}$, which represents a lifetime burden of dental conditions from that age onward, was estimated to be $0.43 \mathrm{y}$, representing 5.3\% of QALE loss due to overall morbidity. A clear social gradient in QALE loss due to dental conditions across the life course was observed. Dental conditions shared a larger proportion of QALE loss due to overall morbidity among lower educated people, suggesting that dental conditions have a relatively higher impact among the lower socioeconomic group.

The impact of dental health on QALE can be put into context when compared to the respective estimates for other health outcomes. At a population level, QALE loss is reported to be $1.9 \mathrm{y}$ for diabetes, $1.2 \mathrm{y}$ for heart disease, $1.2 \mathrm{y}$ for obesity/ overweight, and 1.9 y for smoking (Jia, Zack, and Thompson 2013; Jia et al. 2016; Jia, Zack, Thompson, et al. 2013). The difference in QALE between those with/without depression is reported to be 28.9 y (Jia et al. 2016); however, populationlevel QALE loss for depression considering the prevalence has not been reported. As the dental-related QALE loss $(0.43 \mathrm{y})$ reached approximately a third or fourth of these major causes of health burden, the burden of dental conditions on quality of life is substantial, although they are somewhat neglected in public health policies (Allukian 2008). The distributional aspect of health care resource allocation in society needs to be 
Table 3. Quality-Adjusted Life Expectancy Loss Due to Oral Conditions, at Age 20 y.

\begin{tabular}{|c|c|c|c|c|c|c|c|c|c|c|}
\hline & \multicolumn{10}{|c|}{ QALE Loss, y } \\
\hline & \multicolumn{2}{|c|}{ Overall Morbidity } & \multicolumn{2}{|c|}{ All Oral Conditions } & \multicolumn{2}{|c|}{ Decayed Teeth } & \multicolumn{2}{|c|}{ Missing Teeth } & \multicolumn{2}{|c|}{ Periodontitis $^{\mathrm{a}}$} \\
\hline & $\begin{array}{c}\text { Point } \\
\text { Estimate }\end{array}$ & $95 \% \mathrm{Cl}^{\mathrm{b}}$ & $\begin{array}{c}\text { Point } \\
\text { Estimate }\end{array}$ & $95 \% \mathrm{Cl}^{\mathrm{b}}$ & $\begin{array}{c}\text { Point } \\
\text { Estimate }\end{array}$ & $95 \% \mathrm{Cl}^{\mathrm{b}}$ & $\begin{array}{c}\text { Point } \\
\text { Estimate }\end{array}$ & $95 \% \mathrm{Cl}^{\mathrm{b}}$ & $\begin{array}{c}\text { Point } \\
\text { Estimate }\end{array}$ & $95 \% \mathrm{Cl}^{\mathrm{b}}$ \\
\hline \multicolumn{11}{|l|}{ Both } \\
\hline All & 8.15 & 8.03 to 8.27 & 0.43 & 0.28 to 0.59 & 0.14 & 0.07 to 0.22 & 0.31 & 0.19 to 0.45 & -0.02 & -0.07 to 0.03 \\
\hline High school or less & 8.71 & 8.45 to 8.95 & 0.57 & 0.36 to 0.76 & 0.21 & 0.10 to 0.33 & 0.39 & 0.24 to 0.56 & -0.04 & -0.11 to 0.03 \\
\hline Less than college & 7.32 & 7.17 to 7.48 & 0.38 & 0.24 to 0.51 & 0.12 & 0.06 to 0.19 & 0.28 & 0.18 to 0.40 & -0.03 & -0.07 to 0.02 \\
\hline College or more & 7.83 & 7.56 to 8.12 & 0.25 & 0.15 to 0.35 & 0.07 & 0.03 to 0.13 & 0.18 & 0.10 to 0.27 & -0.01 & -0.04 to 0.03 \\
\hline \multicolumn{11}{|l|}{ Men } \\
\hline All & 7.35 & 7.20 to 7.51 & 0.41 & 0.26 to 0.57 & 0.16 & 0.08 to 0.25 & 0.29 & 0.18 to 0.41 & -0.03 & -0.09 to 0.03 \\
\hline High school or less & 7.69 & 7.39 to 8.00 & 0.54 & 0.34 to 0.74 & 0.24 & 0.12 to 0.37 & 0.35 & 0.21 to 0.50 & -0.05 & -0.13 to 0.04 \\
\hline Less than college & 6.56 & 6.37 to 6.78 & 0.36 & 0.23 to 0.50 & 0.13 & 0.06 to 0.21 & 0.26 & 0.16 to 0.37 & -0.03 & -0.09 to 0.03 \\
\hline College or more & 7.28 & 6.97 to 7.70 & 0.26 & 0.15 to 0.37 & 0.08 & 0.04 to 0.15 & 0.19 & 0.10 to 0.28 & -0.01 & -0.05 to 0.04 \\
\hline \multicolumn{11}{|l|}{ Women } \\
\hline All & 8.96 & 8.76 to 9.16 & 0.44 & 0.28 to 0.59 & 0.12 & 0.06 to 0.18 & 0.34 & 0.20 to 0.48 & -0.02 & -0.05 to 0.02 \\
\hline High school or less & 9.88 & 9.49 to 10.31 & 0.60 & 0.39 to 0.80 & 0.18 & 0.09 to 0.29 & 0.45 & 0.27 to 0.63 & -0.03 & -0.08 to 0.02 \\
\hline Less than college & 8.11 & 7.88 to 8.34 & 0.39 & 0.26 to 0.54 & 0.11 & 0.05 to 0.17 & 0.31 & 0.19 to 0.43 & -0.02 & -0.05 to 0.02 \\
\hline College or more & 8.32 & 7.94 to 8.75 & 0.22 & 0.13 to 0.32 & 0.06 & 0.03 to 0.12 & 0.17 & 0.10 to 0.26 & -0.01 & -0.03 to 0.01 \\
\hline
\end{tabular}

$\mathrm{Cl}$, confidence interval; QALE, quality-adjusted life expectancy.

${ }^{a}$ The number of teeth with pocket depth $\geq 4 \mathrm{~mm}$ and loss of attachment $\geq 3 \mathrm{~mm}$ on the same periodontal site.

Estimated using bootstrapping with 2,000 repetitions.

assessed considering the obvious social gradient in dentalrelated QALE loss and that larger share of dental-related QALE loss among the lower socioeconomic population. Policies should follow the proportionate universalism principle (Marmot et al. 2010).

Social gradients in oral health have been reported in both clinical and subjective outcomes (Sheiham et al. 2011). The pattern of the gradient is complex, and it varies by socioeconomic and oral health indicators and countries. For example, a study in the United Kingdom reported that the difference in caries prevalence by income was greater in the younger age group, whereas differences by income in missing teeth increased with aging (Steele et al. 2015). The gradient could be narrower in the countries like the United Kingdom where dental health care is covered by universal health coverage (Guarnizo-Herreño et al. 2015). On the other hand, water fluoridation is widely established in the United States, and this could contribute to a reduction in inequalities in QALE loss due to dental caries and possibly tooth loss. However, $33 \%$ of adults and $12 \%$ of children in the United States did not have dental insurance in 2013 (Nasseh and Vujicic 2015). Absence of dental insurance is a barrier to access routine dental care and might have resulted in leaving caries untreated. Ensuring access to dental care for the entire population may at least partially reduce the burden of dental conditions. Several studies reported that social gradients in edentulism in the United States have been narrowing, whereas that in untreated decay and the number of missing teeth have been widening (Wu et al. 2014; Farmer et al. 2016). The social gradient in the present study in QALE loss for each age group widened until early older age, and then it remained stable for those aged $60 \mathrm{y}$ or older. The widening gradient was provided by disutility from the number of missing teeth, suggesting that the social pattern in total dental health burden is driven by accumulating moderate differences (e.g., untreated caries or 1 additional missing tooth) rather than total tooth loss occurring later in life. Policies focusing on preventing a moderate suboptimal dental condition starting from earlier stages of life could reduce social inequalities in dental-related QALE loss, for example, extending years of education (Matsuyama et al. 2018) and/or taxing sugar-sweetened beverages/foods (Colchero et al. 2016).

The effect size of missing teeth was smaller among the older population, but that of decayed teeth was larger among them. This suggests that older people could have adapted and become more tolerant of tooth loss (MacEntee et al. 1997). A study reporting an inverse association between aging and Oral Health Impact Profile (OHIP-14) score among adults with clinical conditions (Slade and Sanders 2011) would support this adaptation. The age difference in decayed teeth could be explained by its severity: the number of untreated surfaces per 1 untreated tooth was higher among older people (results not shown). The nonsignificant association between periodontitis and disutility is in line with a systematic review reporting that the impact of periodontal disease on the general quality of life was inconclusive (Haag et al. 2017). It should be noted that QALE is not the only criterion to determine a condition to be prevented/treated, and periodontal diseases, as a "silent" disease, should also be prioritized to reduce the resulting tooth loss.

A few population studies have estimated utility scores for dental conditions, although none have reported QALE loss. Having gingivitis and $\geq 6 \mathrm{~mm}$ of loss of attachment were associated with lower EQ-5D scores by 0.001 and 0.012 , respectively; however, confounding factors have not been adjusted for (Brennan et al. 2007). Jamieson et al. (2017) reported a 
0.037 lower EQ-5D score for people with $<21$ teeth compared to those with 21 or more teeth among the Australian population. The association reported in that study is larger than our result. This might be because the study population was healthier in the Australian study (average disutility score $=0.09$ ) than the present study (average disutility score $=0.14$ ). Dental conditions might have a larger impact on quality of life among healthier populations.

Disability-adjusted life years (DALYs) is another metric to evaluate and compare different diseases' impact on the population. The disability weights for symptomatic caries, total tooth loss, and severe periodontal disease have been reported as $0.010,0.067$, and 0.007, respectively (Salomon et al. 2015), which were larger than the coefficients from our regression analyses. The DALY for all oral conditions in the United States was estimated at 0.003 y per person in 2015 (Kassebaum et al. 2017). Although our estimate focused on 3 dental conditions, our estimate of QALE was much larger than the DALY estimation. There are some potential explanations for these differences. First, disability weights have a predominantly functional focus on each oral condition (e.g., "a toothache, which causes some difficulty eating" for untreated symptomatic caries and "great difficulty in eating meat, fruits, and vegetables" for total tooth loss; Kassebaum et al. 2017); however, the social aspect is also an important pathway linking oral conditions and general quality of life (Allen 2003). The utility score focuses on impact to overall quality of life, which is a wider construct and could also include social aspects of oral health. Our additional analyses showed that "feeling embarrassed because of mouth" explained the considerable extent of the association between missing teeth and disutility score (Appendix Table 2). Also, a systematic review reported that loss of anterior teeth had a larger impact on quality of life than posterior teeth (Gerritsen et al. 2010). Second, the criteria of dental conditions were more extreme when estimating disability weights than the present study. This might also underestimate the burden of dental conditions as they affect considerably the quality of life of people before these excessive thresholds; for example, tooth loss in general (rather than total tooth loss) has been shown to negatively affect the oral health-related quality of life (Gerritsen et al. 2010). Furthermore, our additional analyses showed that the marginal effect of 1 additional missing tooth was not statistically significant after a person lost $>8$ teeth, which corresponds to losing functional dentition (Appendix Fig. 2). This suggests the importance of capturing the burden of moderate but more prevalent dental problems. Third, disability weights are estimated from the questionnaire survey for the general population, including people with and also without dental problems. People without dental problems might underestimate the potential burden of it. Another explanation is related to methodological differences, such as age weighting in the DALY estimations, where young or older populations have a lower weight.

This study has some limitations. First, our analyses were based on pooled data from 3 cross-sectional surveys; thus, our results could partly be due to reverse causation. There were some differences in the dental assessment procedure by waves (e.g., partial-mouth periodontal assessment was conducted on people aged $\geq 18$ y in waves 2001 and 2003, while full-mouth periodontal assessment was conducted on people aged $\geq 30 \mathrm{y}$ ). Accordingly, the participants aged between 20 and 29 y were from wave 2001 or 2003. Also, there could be confounders that we did not address; for example, deprivation could be associated with both dental conditions and disutility scores, and this may go beyond the influence of educational attainment (Locker 2000). Second, the study population was sampled from noninstitutionalized people, and those who had a certain medical condition were excluded from the clinical examination. Note that our analysis applies only to the impacts of caries, periodontitis, and tooth loss but not to other oral conditions such as oral cancer. The impact of oral conditions would be larger if those less healthy population groups and additional oral health conditions were included. Our study may therefore be considered to provide only lower bound estimates for the impact of oral conditions on people's quality of life. Third, we used continuous variables for dental conditions. The association between periodontitis and disutility score could be underestimated as we used the information from the partial-mouth assessment. However, our sensitivity analyses using full-mouth assessment information in 2011 also showed an insignificant association between periodontitis and disutility score (Appendix Table 3). Sensitivity analyses indicated that categorized clinical variables would reveal similar findings (Appendix Table 4). Smoking and diabetes are mainly associated with periodontitis but not dental caries. The model without adjusting for these covariates showed a similar result (Appendix 5). Fourth, we used the data originating from 2001 to 2012. Our estimates might not fully reflect recent improvements in dental conditions, while social inequalities in dental diseases have continued to widen (Rozier et al. 2017). This may imply that the overall societal burden of dental diseases on people's quality of life may not necessarily be lower if estimated on basis of more recent data. Fifth, our dependent variable, disutility score, was derived from the questions on unhealthy days and self-rated health. These questions might not capture all aspects of dental problems. In this sense, QALE loss due to dental conditions in the present study would be underestimated.

\section{Conclusion}

This study estimated dental-related QALE loss in the US adult population. Population health is certainly compromised by dental conditions, and obvious social gradients at all age groups exist. The study findings highlight the necessity for multisectoral public health strategies across the life course to promote oral health and tackle oral health inequalities.

\section{Author Contributions}

Y. Matsuyama, contributed to conception, design, data analysis and interpretation, drafted the manuscript; G. Tsakos, R.G. Watt, 
contributed to conception, design, data interpretation, critically revised the manuscript; S. Listl, J. Aida, contributed to data interpretation, critically revised the manuscript. All authors gave final approval and agree to be accountable for all aspects of the work.

\section{Acknowledgments}

The authors gratefully acknowledge the participants in the NHANES surveys. This work was supported by grants from the Grant-in-Aid for JSPS Research Fellow (17J05974). The authors declare no potential conflicts of interest with respect to the authorship and/or publication of this article.

\section{ORCID iD}

Y. Matsuyama iD https://orcid.org/0000-0002-6114-5604

\section{References}

Allen PF. 2003. Assessment of oral health related quality of life. Health Qual Life Outcomes. 1:40.

Allukian M Jr. 2008. The neglected epidemic and the surgeon general's report: a call to action for better oral health. Am J Public Health. 98(Suppl 1): $82-85$.

Brennan DS, Spencer AJ, Roberts-Thomson KF. 2007. Quality of life and disability weights associated with periodontal disease. J Dent Res. 86(8): $713-717$

Brooks R. 1996. EuroQol: the current state of play. Health Policy. 37(1):53-72.

Centers for Disease Control and Prevention. 2004. Trends in oral health status: United States, 1988-1994 and 1999-2004. Hyattsville, MD: National Center for Health Statistics.

Centers for Disease Control and Prevention. 2012. National Health and Nutrition Examination Survey (NHANES) Oral Health Examiners Manual [accessed 2019 Feb 4]. https://www.cdc.gov/nchs/nhanes/index.htm.

Colchero MA, Popkin BM, Rivera JA, Ng SW. 2016. Beverage purchases from stores in Mexico under the excise tax on sugar sweetened beverages: observational study. BMJ. 352:h6704.

Farmer J, McLeod L, Siddiqi A, Ravaghi V, Quiñonez C. 2016. Towards an understanding of the structural determinants of oral health inequalities: comparative analysis between Canada and the United States. SSM Popul Health. 2:226-236.

Gerritsen AE, Allen PF, Witter DJ, Bronkhorst EM, Creugers NHJ. 2010. Tooth loss and oral health-related quality of life: a systematic review and metaanalysis. Health Qual Life Outcomes. 8:126.

Gheorghe M, Wubulihasimu P, Peters F, Nusselder W, Van Baal PH. 2016. Health inequalities in the Netherlands: trends in quality-adjusted life expectancy (QALE) by educational level. Eur J Public Health. 26(5):794-799.

Guarnizo-Herreño CC, Tsakos G, Sheiham A, Marmot MG, Kawachi I, Watt RG. 2015. Austin Powers bites back: a cross sectional comparison of US and English national oral health surveys. BMJ. 351:h6543.

Haag DG, Peres KG, Balasubramanian M, Brennan DS. 2017. Oral conditions and health-related quality of life: a systematic review. J Dent Res. 96(8):864-874

Heilmann A, Tsakos G, Watt RG. 2015. Oral health over the life course. In Ûrton-Jeangros C, Cullati S, Sacker A, Blane D, editors. A life course perspective on health trajectories and transitions. New York, NY: Springer International. p. 39-59.

Jamieson L, Brennan D, Peres MA, Luzzi L, Miller C, Bowden J, McCaffrey N. 2017. Having fewer than 21 teeth associated with poorer general health among South Australians. J Public Health Dent. 77(3):216-224.

Jia H, Zack MM, Moriarty DG, Fryback DG. 2011. Predicting the EuroQol group's EQ-5D index from CDC's "Healthy Days" in a US sample. Med Decis Making. 31(1):174-185.
Jia H, Zack MM, Thompson WW. 2013. The effects of diabetes, hypertension, asthma, heart disease, and stroke on quality-adjusted life expectancy. Value Health. 2(2):147-185.

Jia H, Zack MM, Thompson WW, Crosby AE, Gottesman II. 2016. Impact of depression on quality-adjusted life expectancy (QALE) directly as well as indirectly through suicide. Soc Psychiatry Psychiatr Epidemiol. 50(6):939-949.

Jia H, Zack MM, Thompson WW, Dube SR. 2013. Quality-adjusted life expectancy (QALE) loss due to smoking in the United States. Qual Life Res. 22(1):27-35.

Kassebaum NJ, Smith AGC, Bernabé E, Fleming TD, Reynolds AE, Vos T, Murray CJL, Marcenes W; GBD 2015 Oral Health Collaborators. 2017. Global, regional, and national prevalence, incidence, and disabilityadjusted life years for oral conditions for 195 countries, 1990-2015: a systematic analysis for the global burden of diseases, injuries, and risk factors. J Dent Res. 96(4):380-387.

Locker D. 2000. Deprivation and oral health: a review. Community Dent Oral Epidemiol. 28(3):161-169.

Love-Koh J, Asaria M, Cookson R, Griffin S. 2015. The social distribution of health: estimating quality-adjusted life expectancy in England. Value Health. 18(5):655-662.

MacEntee MI, Hole R, Stolar E. 1997. The significance of the mouth in old age. Soc Sci Med. 45(9):1449-1458.

Marmot MG, Allen J, Goldblatt P, Boyce T, McNeish D, Grady M, Geddes I, Caan W. 2010. Fair society, healthy lives: strategic review of health inequalities in England post-2010. The Marmot Review [accessed $2019 \mathrm{Feb} 4]$. http:// www.instituteofhealthequity.org/resources-reports/fair-society-healthylives-the-marmot-review/fair-society-healthy-lives-full-report-pdf.pdf

Matsuyama Y, Jürges H, Listl S. 2018. The causal effect of education on tooth loss: evidence from United Kingdom schooling reforms. Am J Epidemiol. 188(1):87-95

Nasseh K, Vujicic M. 2015. Dental benefits coverage rates increased for children and young adults in 2013. Heal Policy Inst Res Brief Am Dent Assoc [accessed 2019 Feb 4]. http://www.ada.org/ /media/ADA/Science\%20 and\%20Research/HPI/Files/HPIBrief 1015 3.ashx

Neumann PJ, Cohen JT. 2018. QALYs in 2018-advantages and concerns. JAMA. 319(24):2473-2474.

Nicolau B, Thomson WM, Steele JG, Allison PJ. 2007. Life-course epidemiology: concepts and theoretical models and its relevance to chronic oral conditions. Community Dent Oral Epidemiol. 35(4):241-249.

Rosenberg MA, Fryback DG, Lawrence WF. 1999. Computing populationbased estimates of health-adjusted life expectancy. Med Decis Making. 19(1):90-97.

Rozier RG, White A, Slade G. 2017. Trends in oral diseases in the U.S. population. J Dent Educ. 81(8s):e97-e109.

Salomon JA, Haagsma JA, Davis A, de Noordhout CM, Polinder S, Havelaar AH, Cassini A, Devleesschauwer B, Kretzschmar M, Speybroeck N, et al. 2015. Disability weights for the Global Burden of Disease 2013 study. Lancet Global Health. 3(11):e712-e723.

Sheiham A, Alexander D, Cohen L, Marinho V, Moysés S, Petersen PE, Spencer J, Watt RG, Weyant R. 2011. Global oral health inequalities: task group-implementation and delivery of oral health strategies. Adv Dent Res. 23(2):259-267.

Slade GD, Sanders AE. 2011. The paradox of better subjective oral health in older age. J Dent Res. 90(11):1279-1285.

Steele J, Shen J, Tsakos G, Fuller E, Morris S, Watt R, Guarnizo-Herreño C, Wildman J. 2015. The interplay between socioeconomic inequalities and clinical oral health. J Dent Res. 94(1):19-26.

Watt R, Listl S, Peres M, Heilmann A. 2015. Social inequalities in oral health: from evidence to action. London, UK: International Centre for Oral Health Inequalities Research and Policy.

Whitehead SJ, Ali S. 2010. Health outcomes in economic evaluation: the QALY and utilities. Br Med Bull. 96(1):5-21.

Wu B, Hybels C, Liang J, Landerman L, Plassman B. 2014. Social stratification and tooth loss among middle-aged and older Americans from 1988 to 2004. Community Dent Oral Epidemiol. 42(6):495-502.

Xu J, Kochanek KD, Murphy SL. 2015. National vital statistics reports deaths: final data for 2011. Statistics (Ber). 63(3):135. 